\title{
Neoadjuvant Laparoscopic HIPEC combined with Neoadjuvant Chemotherapy followed by Surgery plus intraoperative HIPEC for Advanced Gastric Cancer at risk of Peritoneal Carcinomatosis: feasibility and safety assessment from retrospective case control study
}

Maneesh Kumarsing Beeharry

Shanghai Jiao Tong University Medical School Affiliated Ruijin Hospital Zhen Tian Ni

Shanghai Jiao Tong University Medical School Affiliated Ruijin Hospital

Wen Tao Liu ( $\sim$ superliuwentao2019@163.com )

Shanghai Jiao Tong University Medical School Affiliated Ruijin Hospital https://orcid.org/0000-00032871-9650

\section{Xue Xin Yao}

Shanghai Jiao Tong University Medical School Affiliated Ruijin Hospital

Min Yan

Shanghai Jiao Tong University Medical School Affiliated Ruijin Hospital

\section{Zheng Gang Zhu}

Shanghai Jiao Tong University Medical School Affiliated Ruijin Hospital

Research

Keywords: Advanced Gastric Cancer; Hyperthermic Intraperitoneal Chemotherapy; Neoadjuvant Chemotherapy; Comprehensive approach

Posted Date: March 12th, 2020

DOI: https://doi.org/10.21203/rs.3.rs-16986/v1

License: (a) (1) This work is licensed under a Creative Commons Attribution 4.0 International License. Read Full License 


\section{Abstract}

Objective: In this study we have retrospectively evaluated the feasibility and safety of a novel therapeutic regimen for the management of Advanced Gastric Cancer (AGC) at risk for peritoneal carcinomatosis (PC) involving neoadjuvant laparoscopic hyperthermic intraperitoneal chemotherapy (NLHIPEC) and neoadjuvant chemotherapy (NAC).

Methods: From December 2017 to June 2018, 7 AGC patients undergoing NLHIPEC + NAC + Surgery+ Intraoperative HIPEC + adjuvant chemotherapy (AC) were included in the study and observed for associated complication and morbidity. AGC patients undergoing other neoadjuvant and prophylactic treatment approaches were retrospectively analyzed and case-matched. Intraoperative and post-operative events, clinical recovery and morbidity were closely monitored till 1 month after the last cycle of chemotherapy.

Results: Of a total of 328 AGC patients undergoing curative surgery, 7 other patients undergoing NAC + HIPEC, 7 patients undergoing surgery + HIPEC and 17 patients undergoing NAC were retrospectively included. There was no 30-day post-operative mortality recorded in the 4 groups. In total, 14 events were recorded and 5/14 of the complications were rated as Clavien I; 8/14 patients were classified as Clavien II and $1 / 14$ patient was recorded as Clavien grade IIla. There was no grade IIIb-V event. The results suggest that the proposed treatment regimen is safe and feasible.

Conclusions: This combination of NLHIPEC and NAC in the management of AGC at high risk for peritoneal involvement is feasible, safe, well-tolerated and worth exploring.

\section{Background}

Gastric cancer (GC) is the fourth most common malignancy worldwide ${ }^{[1]}$ but almost half of GC-related deaths in the world occur in China ${ }^{[2]}$. However, despite the triggering advances in medical research and technology, the prognosis of the advanced stages of GC (AGC) remains poor. Where systemic adjuvant radio-chemotherapy following surgery of curative intent has increased overall survival (OS) rate by $32 \%$ and progression-free survival (PFS) rate by $51 \%{ }^{[3]}$, the implementation of chemotherapy prior to surgery has been reported to decrease mortality by $25 \%$ and disease progression by $34 \%{ }^{[4]}$. Nevertheless, the post-operative metastasis or disease recurrence rates are still relatively high with the peritoneum still presiding as a common site of treatment failure for AGC ${ }^{[5]}$ : it has been previously reported that at time of death, $60 \%$ of GC patients presented with peritoneal dissemination which caused significant quality of life impairment from complications such as tense ascites, malignant bowel obstruction, malnutrition and cachexia ${ }^{[5-6]}$. Chemotherapy and immunotherapy alone have limited efficacy against peritoneal carcinomatosis ${ }^{[7-9]}$. Thus, multimodality strategies including various combinations of systemic chemotherapy and hyperthermic intraperitoneal chemotherapy (HIPEC) have been studied to improve survival and prevent morbid complications. 
From the very first report about the role of HIPEC in the prevention of peritoneal dissemination in AGC due to surgical trauma or disease progression by Koga et al. in 1988, the application of the combination of regional chemotherapy enhanced with hyperthermia and continuous mechanical erosion of free peritoneal cancer cells has been vividly advocated over the last few decades ${ }^{[10-12]}$. Our personal experience with HIPEC as prophylaxis against secondary peritoneal carcinomatosis (PC) has shown better survival rate and peritoneal metastasis prevention in cases with intraoperative HIPEC ${ }^{[13-15]}$. Over the last few decades, neoadjuvant chemotherapy (NAC) has also gained recognition where NAC before curative resection has shown the potential benefits of primary tumor down-staging and lymph node metastasis and occult micro-metastases control in GC patients with better tolerance in the pre-operative stages ${ }^{[16]}$. In 2013, a Cochrane single patient data meta-analysis including 14 randomized trials showed an improvement in overall survival $(\mathrm{HR}=0.81,95 \% \mathrm{Cl}: 0.79-0.89, \mathrm{P}<0.0001)$ with a 5 -year survival gain of $9 \%$ with a 1.4 times radical resection rate favoring the NAC arm ${ }^{[17]}$. With NAC showing promising survival benefit and favorable surgical radicality, it has been widely accepted in Western countries as prophylaxis against post-operative recurrence. Along the same line, with HIPEC has also been gaining more recognition in the intra-operative prophylactic setting, there has been speculation about the possibility of the efficacy of HIPEC in the neoadjuvant setting as prophylaxis against PC in patients with AGC at high risks or with occult peritoneal dissemination at the time of diagnosis. With the optimization of the comprehensive treatment modality for AGC, the option of combining NAC's tumor down-staging and HIPEC's prophylactic against peritoneal dissemination was explored. In a study by Cui et al., the combination of NAC with HIPEC for the treatment of AGC was well tolerated and exhibited improved compliance and efficiency with survival benefit ${ }^{[18]}$. In a study by Coccolini et al., prophylactic HIPEC associated to NAC increased the DFS and OS in patients with AGC without carcinomatosis [19]. Nevertheless, there have been more reports about the combination of NAC followed by HIPEC improving the survival rates in ovarian cancer ${ }^{[20-21]}$. On the other hand, there have been fewer reports about the efficacy of laparoscopic HIPEC (L-HIPEC): in a report by Yonemura et al., L-HIPEC combined with

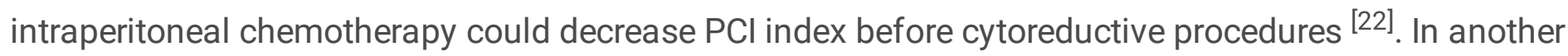
report by Baslescu el al., they used laparoscopy for the cytoreductive surgery (L-CRS) and L-HIPEC) to emphasize the advantages of minimal invasive surgery and contributed to improved postoperative outcomes ${ }^{[23]}$. Nevertheless, the role of HIPEC in the neoadjuvant setting has not been investigated in clinical trials.

With the role of HIPEC established as a prophylaxis against PC, we now hypothesize that HIPEC in the neoadjuvant setting combined with NAC will not only support tumor down-sizing and down-staging, but will also manage and treat occult peritoneal dissemination since the rate of detection of peritoneal lavage cytology is relatively low in clinical practice. Therefore, in an attempt for a more comprehensive approach for the management of AGC, irrespective of positive or negative peritoneal lavage cytology, our research team proposes the Dragon II regimen which involves neoadjuvant laparoscopic HIPEC (NLHIPEC) combined with NAC followed by surgery of curative intent with intraoperative HIPEC and then followed by adjuvant chemotherapy (AC). With an intention to treat, this approach was applied in clinical practice and 
in this study, we have retrospectively investigated the feasibility and safety of the suggested experimental regimen as compared to already established prophylactic and neoadjuvant approaches approached carried out in our institution.

\section{Patients And Methods}

Between December 2017 and June 2018, 7 AGC patients were screened and subjected to a comprehensive neoadjuvant treatment regimen involving 1 cycle of NLHIPEC followed by 3 cycles of NAC followed by surgery of curative intent with intraoperative HIPEC followed by 5 cycles of adjuvant chemotherapy. After 1 year of follow-up, we retrospectively investigated all the AGC patients undergoing neoadjuvant and intraoperative prophylactic treatment over the same period of time. The main forms of neoadjuvant and prophylactic treatment recorded were 3 cycles of NAC followed by surgery with intraoperative HIPEC then AC; surgery plus intraoperative prophylactic HIPEC and 3 cycles of NAC followed by surgery and AC. Hence, after conducting thorough patient file review, we separated the cases into 4 groups: the Experiment group, the NAC + HIPEC group, the Surgery + HIPEC group and the NAC group.

\section{Ethics approval and consent to participate}

This study has been approved by the Ethics Committee of Ruijin Hospital affiliated to Shanghai Jiao Tong University School of Medicine. All participating subjects will sign the written consent form. All patients included in the experimental group conformed to the following list of inclusion Criteria: (1)Aged between 18 and 75 years old; (2) Eastern Cooperative Oncology Group (ECOG) score $\leq 2 ;(3)$ American Society of Anesthesiologists (ASA) grades I-III;(4) Primary GC without prior history of gastric malignancy; (5) Multiple detector computed tomography (MDCT), Endoscopic Ultrasonography or Laparoscopic Exploration revealing lesion(s) infiltrating the serosal (T staging T4); (6) Normal Bone Marrow, Liver, Renal functions conforming to the following standards:(a) Peripheral blood white blood cells (WBC) count $\geq 3500 / \mathrm{mm}^{3}$, platelet count (PLT) $\geq 100,000 / \mathrm{mm}^{3}$ and hemoglobin count $(\mathrm{Hb}) \geq$ $90 \mathrm{~g} / \mathrm{L} ;(\mathrm{b})$ Total bilirubin $\leq 1.5$ times the upper limit of normal (ULN); Aspartate aminotransferase (AST) and alanine aminotransferase (ALT) $\leq 2.5 \times \mathrm{ULN}$; Serum creatinine $(\mathrm{SCr}) \leq 50 \mathrm{ml} / \mathrm{min}$.(7) Negative urine or blood pregnancy test for female subjects of childbearing potential; (8) Expected life expectancy $\geq 3$ months; (9) willing to sign inform consent for participation and publication of results.

Grouping and Treatment (see Fig. 1 for Experiment Layout): Insert Figure 1 here.

Arm A (L-HIPEC Group): Laparoscopic Exploration + L-HIPEC + 3 cycles of NAC + standard D2 gastrectomy + intraoperative HIPEC + 3-5 cycles of AC.

Arm B (NAC + HIPEC + Surgery): 3 cycles of NAC + standard D2 gastrectomy + intraoperative HIPEC + 3-5 cycles of AC.

Arm C (Surgery + HIPEC) :Standard D2 Gastrectomy + intraoperative HIPEC + 6-8 cycles of AC. 
Arm D (NAC + Surgery):3 cycles of NAC + standard D2 gastrectomy + 3-5 cycles of AC.

L-HIPEC Procedure The equipment for the laparoscopic and intraoperative procedures is the BR-TRG-I Hyperthermic Perfusion Intraperitoneal Treatment system (Baorui Medical Technology, Co., Ltd., Guangzhou, China). The laparoscopic HIPEC technique consists in through $15 \mathrm{~mm}$ trocars placing two inflow catheters in the upper abdominal region and two outflow catheters in the Douglas pouch, each catheter being connected to the corresponding thermo-probe. Once the randomization is performed and verified, the L-HIPEC procedure is started, a $43^{\circ} \mathrm{C}$ solution of Paclitaxel $80 \mathrm{mg} / \mathrm{m}^{2}$ being introduced into the peritoneal cavity and re-circulated for 60 minutes at a flow rate controlled between $400-600 \mathrm{ml}$. The chemotherapeutic agent is introduced on the two inflow catheters which are placed in the upper abdominal quadrant, in the proximity of the tumor bed and aspirated on the two outflow catheters which were placed in the Douglas pouch. The intra-abdominal temperature is monitored during the procedure by the four thermocouples which are placed at the level of the inflow and respectively of the outflow catheters, with an intra-abdominal probe maintaining an intraperitoneal temperature of $43 \pm 1^{\circ} \mathrm{C}$. In the meantime, the endo-esophageal temperature level is closely monitored (a value higher than $39^{\circ} \mathrm{C}$ enforcing ending the procedure). After the procedure, the 4 catheters are removed and the trocars incisions closed.

Neoadjuvant Chemotherapy The NAC regimens for Arms A and B was EOX, consisting of Oxaliplatin, Epirubicin, Capecitabine/Xeloda. Oxaliplatin $130 \mathrm{mg} / \mathrm{m}^{2}$ and Epirubicin $50 \mathrm{mg} / \mathrm{m}^{2}$ were administered intravenously on day 1.Capecitabine / Xeloda was administered orally $1500 \mathrm{mg} / \mathrm{m}^{2}$, twice a day for 14 consecutive days, followed by a 7-day rest period.

Adjuvant Chemotherapy The AC regimen in Arms A, B and C was XELOX, Oxaliplatin $130 \mathrm{mg} / \mathrm{m}^{2}$ administered intravenously on day 1 and Capecitabine / Xeloda administered orally $1500 \mathrm{mg} / \mathrm{m}^{2}$, twice a day for 14 consecutive days, followed by a 7-day rest period.

Intraoperative HIPEC After the anastomosis, the open coliseum technique was used, using Paclitaxel at a dose of $80 \mathrm{mg} / \mathrm{m}^{2}$ dissolved in $3-5 \mathrm{I}$ of normal saline heated to $43{ }^{\circ} \mathrm{C}$, and infused into the abdominal cavity and re-circulated for 60 minutes at a flow rate controlled between 400-600 ml. After the HIPEC procedure, the abdomen is closed.

Tumor response and toxicity criteria Tumor response evaluation in Arms B and C was carried out after the 3rd cycle of preoperative NAC by using abdominal MDCT scan according to the Response Evaluation Criteria for Solid Tumors (RECIST) $1.1^{[24]}$. Therapeutic response would be imageologically and clinically assessed positive in patients with complete remission (CR), partial remission (PR), stable disease (SD) or with clinical benefit. Patients with progressive disease (PD) would be referred to a panel of multidisciplinary team for a more comprehensive assessment of the treatment plan. Adverse events were assessed according to Common Terminology Criteria for Adverse Event (CTCAE) v5.0 [25]. 
End-points The primary endpoint was 1 month post the last cycle of chemotherapy. In-hospital perioperative complications were studied as secondary endpoints. Postoperative complications were classified based on the therapy-oriented severity grading system (TOSGS) and $\mathrm{NCl}$ Common Terminology Criteria (CTC) for Adverse Events version 4.0. Postoperative morbidity was analyzed according to the Dindo-Clavien classification for surgical complications ${ }^{[26]}$.

Statistical analysis All data were systematically collected to establish a comprehensive database of clinical records, surgical and pathology reports, image examination and laboratory reports, and follow-up records. The data were analyzed by SPSS software for windows, version 19.0 (SPSS Inc., Chicago, IL, USA). A two-sided $P<0.05$ was considered as statistically significant.

\section{Results}

1. Clinicopathological Characteristics of the subjects Between December 2017 and June 2018, 7 AGC patients undergoing L-HIPEC + NAC + Surgery + Intraoperative HIPEC + AC were included in the study. During the retrospective case control analysis, we screened a total of 328 cases of GC undergoing gastrectomy of curative intent in our department and after excluding the non-AGC cases, AGC cases directly undergoing surgery and $A G C$ cases undergoing experimental study for other treatment regimens, 7 AGC patients undergoing NAC followed by surgery of curative intent with intraoperative prophylactic HIPEC, 7 AGC patients undergoing surgery of curative intent with intraoperative prophylactic HIPEC and 17 AGC patients undergoing NAC followed by surgery of curative intent were retrospectively analyzed (see Fig. 2 for Flow Diagram).

Insert Figure 2 here.

There were in total 30 male and 8 female patients included in the study. The mean age in each group was 55 years for the L-HIPEC group, 53 years for the NAC + HIPEC group, 63 years for the Surgery + HIPEC group and 65 years for the NAC + Surgery group. The median KPS was over 80 for all patients. When analyzing the pathophysiological and biochemical blood parameters of the patients, we set up 2 different baselines: For patients undergoing neoadjuvant and prophylactic treatment, the first baseline was set at inclusion of study before any therapeutic intervention (see Table 1) and the second baseline was set at the time of surgery (Table 2). Basically all the physiological and biochemical blood parameters were wellbalanced at the first baseline. In Table 2 while comparing the pathophysiological and biochemical blood parameters, we found that the ALT and AST of the different groups were significantly different: Upon conducting intergroup comparison, we noted that there was no difference in the AST of the experiment group but the ALT was still different with the 3 groups. However, we noted that the range of the AST from the experiment group was still within the $1 X$ ULN. There was no significant difference in the histology of the lesions, the surgical procedure (distal or total gastrectomy) or rate of lymph node metastasis (Table 3). 
Table 1

Baseline 1 Clinico-pathological Characteristics of the patients undergoing neoadjuvant and prophylactic treatment regimens

\begin{tabular}{|c|c|c|c|c|}
\hline & $\begin{array}{l}\text { L-HIPEC Group }(n= \\
7)\end{array}$ & $\begin{array}{l}\text { NAC + HIPEC Group (n } \\
=7 \text { ) }\end{array}$ & $\begin{array}{l}\text { NAC Group }(n= \\
17)\end{array}$ & $\begin{array}{l}\mathrm{P} \\
\text { value }\end{array}$ \\
\hline Male $(n, \%)$ & $6(86)$ & $6(86)$ & $13(77)$ & \multirow[t]{2}{*}{0.968} \\
\hline Female (n, \%) & $1(14)$ & $1(14)$ & $4(23)$ & \\
\hline $\begin{array}{l}\text { Mean Age (yrs, } \\
\text { Range) }\end{array}$ & $\begin{array}{l}55 \pm 7 \\
(43-66)\end{array}$ & $\begin{array}{l}53 \pm 15 \\
(30-68)\end{array}$ & $\begin{array}{l}65 \pm 8 \\
(47-74)\end{array}$ & 0.074 \\
\hline KPS (Median) & 90 & 90 & 90 & 0.191 \\
\hline BMI $\left(\mathrm{Kg} / \mathrm{m}^{2}\right)$ & $24.0 \pm 4.5$ & $22.8 \pm 2.5$ & $23.3 \pm 2.5$ & 0.744 \\
\hline WBC (x109/L) & $6.1 \pm 1.1$ & $7.4 \pm 2.3$ & $5.3 \pm 1.5$ & 0.144 \\
\hline$N(\%)$ & $64.1 \pm 4.9$ & $63.5 \pm 14.7$ & $56.7 \pm 11.6$ & 0.239 \\
\hline $\mathrm{Hb}(\mathrm{g} / \mathrm{L})$ & $132 \pm 23$ & $130 \pm 30$ & $119 \pm 21$ & 0.384 \\
\hline $\operatorname{PLT}\left(x 10^{9} / \mathrm{L}\right)$ & $226 \pm 52$ & $268 \pm 138$ & $210 \pm 89$ & 0.406 \\
\hline ALT (IU/L) & $21.6 \pm 24.7$ & $21.3 \pm 12.2$ & $19.1 \pm 12.6$ & 0.505 \\
\hline AST(IU/L) & $24.6 \pm 13.7$ & $23.0 \pm 7.5$ & $24.8 \pm 10.3$ & 0.928 \\
\hline GOT(IU/L) & $22.3 \pm 7.2$ & $31.6 \pm 21.9$ & $51.1 \pm 8.0$ & 0.539 \\
\hline TB $(\mu \mathrm{mol} / \mathrm{L})$ & $13.9 \pm 3.6$ & $12.5 \pm 8.2$ & $12.5 \pm 4.2$ & 0.829 \\
\hline $\mathrm{DB}(\mu \mathrm{mol} / \mathrm{L})$ & $2.3 \pm 0.6$ & $2.3 \pm 1.3$ & $2.4 \pm 1.6$ & 0.927 \\
\hline $\mathrm{SCr}(\mu \mathrm{mol} / \mathrm{L})$ & $86.4 \pm 12.1$ & $80.1 \pm 12.6$ & $71.4 \pm 14.5$ & 0.053 \\
\hline Alb (g/L) & $39.6 \pm 2.4$ & $43.3 \pm 12.0$ & $41.9 \pm 16.2$ & 0.384 \\
\hline AFP (ng/ml) & $4.3 \pm 4.4$ & $2.6 \pm 1.2$ & $3.1 \pm 1.3$ & 0.062 \\
\hline CEA (ng/ml) & $149.2 \pm 282.4$ & $2.5 \pm 1.7$ & $6.2 \pm 7.3$ & 0.529 \\
\hline CA125 (U/ml) & $16.4 \pm 9.9$ & $16.4 \pm 11.7$ & $19.1 \pm 16.7$ & 0.876 \\
\hline CA199 (U/ml) & $234.4 \pm 414.3$ & $264.7 \pm 563.9$ & $17.8 \pm 19.4$ & 0.157 \\
\hline
\end{tabular}


Table 2

Baseline 2: Clinico-pathological Characteristics of the patients before surgery

\begin{tabular}{|c|c|c|c|c|c|}
\hline & $\begin{array}{l}\text { L-HIPEC } \\
\text { Group }(n=7)\end{array}$ & $\begin{array}{l}\text { NAC + HIPEC } \\
\text { Group }(n=7)\end{array}$ & $\begin{array}{l}\text { Surgery + HIPEC } \\
\text { Group }(n=7)\end{array}$ & $\begin{array}{l}\text { NAC Group } \\
(n=17)\end{array}$ & $\begin{array}{l}\mathrm{P} \\
\text { value }\end{array}$ \\
\hline Male $(n, \%)$ & $6(86)$ & $6(86)$ & $5(71)$ & $13(77)$ & \multirow[t]{2}{*}{0.876} \\
\hline Female $(\mathrm{n}, \%)$ & $1(14)$ & $1(14)$ & $2(29)$ & $4(23)$ & \\
\hline $\begin{array}{l}\text { Mean Age (yrs, } \\
\text { Range) }\end{array}$ & $\begin{array}{l}55 \pm 7 \\
(43-66)\end{array}$ & $\begin{array}{l}53 \pm 15 \\
(30-68)\end{array}$ & $\begin{array}{l}63 \pm 5 \\
(54-70)\end{array}$ & $\begin{array}{l}65 \pm 8 \\
(47-74)\end{array}$ & 0.060 \\
\hline KPS (Median) & 90 & 90 & 90 & 90 & 0.671 \\
\hline $\mathrm{BMI}\left(\mathrm{Kg} / \mathrm{m}^{2}\right)$ & $25.0 \pm 3.0$ & $22.1 \pm 2.4$ & $23.7 \pm 1.7$ & $23.8 \pm 2.7$ & 0.196 \\
\hline WBC (x109\% & $5.0 \pm 2.3$ & $4.2 \pm 0.5$ & $6.4 \pm 1.4$ & $4.9 \pm 1.6$ & 0.073 \\
\hline$N(\%)$ & $37.7 \pm 7.3$ & $50.3 \pm 8.5$ & $61.9 \pm 6.0$ & $50.7 \pm 12.9$ & 0.076 \\
\hline $\mathrm{Hb}(\mathrm{g} / \mathrm{L})$ & $129 \pm 23$ & $126 \pm 19$ & $124 \pm 24$ & $115 \pm 24$ & 0.476 \\
\hline $\operatorname{PLT}\left(x 10^{9} / \mathrm{L}\right)$ & $158 \pm 57$ & $140 \pm 40$ & $237 \pm 98$ & $179 \pm 57$ & 0.212 \\
\hline ALT (IU/L) & $43.0 \pm 15.8$ & $27.7 \pm 13.2$ & $20.3 \pm 14.1$ & $23.7 \pm 14.4$ & 0.002 \\
\hline AST(IU/L) & $46.7 \pm 18.0$ & $34.1 \pm 16.8$ & $23.0 \pm 9.0$ & $28.4 \pm 10.0$ & 0.007 \\
\hline GOT(IU/L) & $45.4 \pm 19.3$ & $36.4 \pm 13.7$ & $22.7 \pm 18.6$ & $53.7 \pm 19.5$ & 0.651 \\
\hline TB $(\mu \mathrm{mol} / \mathrm{L})$ & $16.4 \pm 6.3$ & $12.5 \pm 4.8$ & $13.1 \pm 2.7$ & $14.0 \pm 4.7$ & 0.465 \\
\hline $\mathrm{DB}(\mu \mathrm{mol} / \mathrm{L})$ & $2.6 \pm 0.8$ & $2.2 \pm 0.8$ & $2.5 \pm 0.6$ & $2.7 \pm 0.9$ & 0.592 \\
\hline $\mathrm{SCr}(\mu \mathrm{mol} / \mathrm{L})$ & $78.1 \pm 14.7$ & $81.7 \pm 18.1$ & $75.4 \pm 17.6$ & $72.6 \pm 12.0$ & 0.558 \\
\hline Alb (g/L) & $39.3 \pm 4.5$ & $39.3 \pm 3.5$ & $38.9 \pm 5.0$ & $36.8 \pm 4.5$ & 0.444 \\
\hline AFP (ng/ml) & $5.0 \pm 3.8$ & $3.1 \pm 1.5$ & $3.0 \pm 1.4$ & $3.2 \pm 1.3$ & 0.191 \\
\hline CEA (ng/ml) & $6.6 \pm 5.9$ & $2.5 \pm 1.7$ & $4.4 \pm 3.1$ & $4.4 \pm 5.2$ & 0.452 \\
\hline CA125 (U/ml) & $18.0 \pm 5.9$ & $11.1 \pm 5.4$ & $12.5 \pm 6.6$ & $15.7 \pm 14.1$ & 0.593 \\
\hline CA199 (U/ml) & $64.6 \pm 74.4$ & $42.4 \pm 90.8$ & $26.7 \pm 30.4$ & $16.0 \pm 19.9$ & 0.225 \\
\hline
\end{tabular}


Table 3

Clinico-pathological Characteristics of the patients after surgery

\begin{tabular}{|c|c|c|c|c|c|}
\hline & $\begin{array}{l}\text { L-HIPEC } \\
\text { Group ( } n= \\
7)\end{array}$ & $\begin{array}{l}\text { NAC + HIPEC } \\
\text { Group }(n=7)\end{array}$ & $\begin{array}{l}\text { Surgery + HIPEC } \\
\text { Group }(n=7)\end{array}$ & $\begin{array}{l}\text { NAC Group } \\
(n=17)\end{array}$ & $\begin{array}{l}P \\
\text { value }\end{array}$ \\
\hline $\begin{array}{l}\text { Duration of Post- } \\
\text { operative Stay (days) }\end{array}$ & 9 & 11 & 8 & 9 & 0.387 \\
\hline \multicolumn{6}{|l|}{ Surgery Characteristics } \\
\hline Distal Gastrectomy & 2 & 5 & 3 & 4 & \multirow[t]{2}{*}{0.157} \\
\hline Total Gastrectomy & 5 & 2 & 4 & 13 & \\
\hline \multicolumn{6}{|c|}{ Post-operative Pathological T Staging } \\
\hline pT0 & 1 & 0 & 0 & 1 & \multirow[t]{5}{*}{0.239} \\
\hline pT1 & 0 & 0 & 0 & 0 & \\
\hline pT2 & 3 & 0 & 0 & 7 & \\
\hline pT3 & 0 & 1 & 1 & 2 & \\
\hline pT4 & 3 & 6 & 6 & 7 & \\
\hline \multicolumn{6}{|c|}{ Post-operative Pathological N Staging } \\
\hline pNO & 4 & 1 & 0 & 5 & \multirow[t]{4}{*}{0.083} \\
\hline $\mathrm{pN} 1$ & 0 & 0 & 2 & 3 & \\
\hline $\mathrm{pN} 2$ & 0 & 2 & 2 & 0 & \\
\hline pN3 & 3 & 4 & 3 & 9 & \\
\hline
\end{tabular}

2. L-HIPEC associated morbidity: The laparoscopic HIPEC procedures were eventless and no patients from the L-HIPEC group presented with fever, abdominal discomfort, gastroparesis, intestinal necrosis, diarrhea or allergic reactions within the one month of observation.

3. Chemotherapy associated morbidity: When comparing the complete blood count and biochemical examinations of the patients from the L-HIPEC, NAC + HIPEC and NAC, there was no signs of hematotoxicity, hepatotoxicity and nephrotoxicity due to chemotherapy. 2 patients from the L-HIPEC group, 2 from the NAC + HIPEC and 1 from the NAC group complained of loss of appetite and occasional nausea during the first 2 days of chemotherapy but the symptoms would subside without special intervention within the $48 \mathrm{~h}$ following drug administration $(P>0.05)$.

4. Overall Morbidity and Mortality: There was no 30-day post-operative mortality recorded in the 4 groups. However, post-operative events were recorded in 14 of the 38 patients from the 4 groups: 2 in the Surgery 
group (14\%), 4 in the NAC group (29\%), 2 in the Surgery + HIPEC group (14\%) and 6 in the NAC group (43\%). The incidence of the most common types of previously reported complications is shown in Table 4. Table 5 shows the analysis of the morbidity recorded in each group assessed according to the Clavien-Dindo classification of surgical complications.

Table 4

Post-operative Morbidity of the small cohort of patients

\begin{tabular}{|lllll|}
\hline Event/Complication & $\begin{array}{l}\text { L-HIPEC } \\
\text { Group }\end{array}$ & NAC+HIPEC Group & Surgery + HIPEC Group & $\begin{array}{l}\text { NAC+Surgery } \\
\text { Group }\end{array}$ \\
\hline Bleeding & 0 & 0 & 0 & 0 \\
\hline Gastroparesis & 0 & 1 & 0 & 0 \\
\hline Fever & 1 & 0 & 1 & 2 \\
\hline Neutropenia & 0 & 0 & 0 & 0 \\
\hline Pancytopenia & 0 & 0 & 0 & 0 \\
\hline Anastomotic Leak & 1 & 1 & 0 & 2 \\
\hline Bowel Obstruction & 0 & 0 & 0 & 0 \\
\hline Intestinal Necrosis & 0 & 0 & 0 & 0 \\
\hline Renal Dysfunction & 0 & 0 & 0 & 0 \\
\hline Liver Dysfunction & 0 & 1 & 1 & 1 \\
\hline Bilirubinemia & 0 & 0 & 0 & 1 \\
\hline Infection & 0 & 0 & 0 & 0 \\
\hline Diarrhea & 0 & 0 & 0 & 0 \\
\hline Wound Dehiscence & 0 & 1 & 0 & 0 \\
\hline Allergic Reactions & 0 & 0 & 0 & 6 \\
\hline Total Events & 2 & 4 & 0 & 0 \\
\hline
\end{tabular}

During the post-operative analysis, in the L-HIPEC group, 1 patients from the L-HIPEC group presented with fever (not exceeding $38.5^{\circ} \mathrm{C}$ ) which normalized without specific intervention and 1 patient presented with change in drain content 4 days post-op, suggesting anastomotic leak to which bed-side continuous abdominal double cannula lavage and low negative pressure drainage was applied for 4 days and the patients made a full-recovery without surgical intervention. In the NAC + HIPEC group, there was 1 case of abnormal liver function which normalized after hepatoprotective treatment; 1 case gastroparesis which involved nasogastric intubation followed by gastrointestinal decompression and treatment with metoclopramide and the patient made a full recovery after 7 days; 1 case of wound dehiscence treatment 
by bedside dressing; and 1 case of anastomotic leak treated by bed-side continuous abdominal double cannula lavage and low negative pressure drainage followed by CT-guided percutaneous drainage of abscess under local anesthesia without surgical intervention. In the Surgery + HIPEC group, 1 patient presented with abnormal liver function the next day of surgery but after intervention with hepatoprotective treatment, liver function normalized within 48 hours. In the NAC group, there were 2 cases of post-op fever not exceeding $38.5^{\circ} \mathrm{C}$ which normalized without specific intervention and 1 case of abnormal liver function which normalized after hepatoprotective treatment, 1 case of mild hyperbilirubinemia which resolved after treatment with ademetionine and 1 case of post-operative pulmonary infection which resolved after intensive course of specific treatment.

According to the Clavien-Dindo classification, $5 / 14$ (36\%, $13 \%$ of all patients) of the complications were rated as Clavien I; $8 / 14$ patients ( $57 \%, 21 \%$ of all patients) were classified as Clavien II and 1/14 patient ( $7 \%, 3 \%$ of all patients) was recorded as Clavien grade Illa complication. No grade IIIb-V event was recorded during the whole experiment. There was no significant statistical difference found in the incidence of Grades I, II and IIla events between the 5 groups (see Table 5).

Table 5

Grading of the Post-operative Morbidity of the small cohort of patients according to Clavien Dindo scale of complications.

\begin{tabular}{|lllllll|}
\hline & $\begin{array}{l}\text { L-HIPEC } \\
\text { Group }\end{array}$ & $\begin{array}{l}\text { NAC+HIPEC } \\
\text { Group }\end{array}$ & Surgery + HIPEC Group & $\begin{array}{l}\text { NAC+Surgery } \\
\text { Group }\end{array}$ & X $^{2}$ & P Value \\
\hline Grade I & 1 & 1 & 1 & 2 & 2.926 & \\
\hline Grade II & 1 & 2 & 1 & 4 & 0.403 \\
\hline Grade IIIa & 0 & 1 & 0 & 0 & \\
\hline
\end{tabular}

5. Other Parameters: The completion rate of the proposed treatment regimen (L-HIPEC + NAC + Surgery + Intraoperative HIPEC + AC) was $86 \% .1$ patient from the L-HIPEC did not complete the courses of adjuvant chemotherapy due to death from undetected brain metastasis at baseline. The median post-operative stay of the 4 groups was 9 days for the L-HIPEC group (7-26 days), 11 days for the NAC + HIPEC group (7-49 days), 8 days for the Surgery + HIPEC group (7-9 days) and 9 days for the NAC group (7-30 days) and the difference was not statistically significant $(P=0.384)$.

\section{Discussion}

The aim of this study was to investigate the feasibility of a more comprehensive and relatively aggressive treatment regimen in the management of locally advanced GC. The efficacy of HIPEC as a prophylaxis against PC primary to disease progression or secondary to surgical trauma has been investigated and supported in previous literature ${ }^{[14,19-22]}$. The role of chemotherapy in the pre-surgical setting with the main goals of tumor down-sizing and down-staging has also been thoroughly investigated and 
acclaimed over the past few decades ${ }^{[27-30]}$. Nevertheless, the peritoneum still presides as a common site of treatment failure for AGC and even after NAC and surgery of curative intent, $60 \%$ of GC patients still have peritoneal dissemination, further suggesting the therapeutic limitations of chemo-radiotherapy and immunotherapy against PC. Therefore, the feasibility and efficacy of more comprehensive therapeutic approaches involving the combination of chemotherapy before and after surgery of curative intent with regional treatment modalities such as HIPEC have been assessed and investigated. In a study by Cui et al., when AGC patients were separated into 4 groups (Control, NAC, HIPEC and combined groups), the median progression-free survival times were $26,28,31$ and 33 months respectively $(\chi 2,14.63 ; P<0.001)$, suggesting that NAC combined with HIPEC for the treatment of AGC is well tolerated and exhibits improved compliance and efficiency ${ }^{[22]}$. Therefore, in this study, we aimed at investigating the feasibility of a comprehensive approach to the treatment of locally advanced GC. The proposed regimen involves one cycle of L-HIPEC followed by NAC, whereby in case of clinical benefit or good treatment response, curative surgery plus intraoperative prophylactic HIPEC is recommended followed by standard adjuvant chemotherapy. With an intention to treat, 7 patients were subjected to treatment regimen with consent. Simultaneously, the patients were retrospectively case-matched with other patients with similar baseline staging but undergoing different treatment regimens, namely NAC followed surgery with intraoperative prophylactic HIPEC, curative surgery with intraoperative prophylactic HIPEC and NAC followed by surgery.

The results of our retrospective study showed that the proposed regimen was well-tolerated as the other comprehensive treatment options for AGC. The completion rate of the proposed regimen was high with an acceptable rate of morbidity. The common complications recorded in the different study groups were instantaneous fever, abnormal liver function, hyperbilirubinemia, wound dehiscence, gastroparesis and anastomotic leak. The experiment group recorded incidence of 1 cases of fever and 1 case of anastomotic leak which resolved by non-surgical approach. Upon comparison with the other groups, the incidence of these complications was found to be statistically insignificant.

Several studies have shown that the combination of NAC with HIPEC for the treatment of ovarian cancer is feasible and reasonably well-tolerated ${ }^{[31-33]}$ : Recently, a phase III clinical trial demonstrated that performing surgery followed by HIPEC improved survival outcomes among patients who had received NAC for stage III epithelial ovarian cancer and the combination of HIPEC resulted in a longer recurrencefree survival and OS compared to surgery alone and did not result in higher rates of postoperative complications. Specific drug toxicity is frequently associated with surgical toxicity in HIPEC but in our study, Paclitaxel (PTX) did not appear to cause any major toxicity compared to other drugs used in HIPEC. PTX has a high molecular weight and is highly metabolized by the liver; thus, it is associated with very low rates of systemic toxicity. Cascales-Campos et al. reported that patients with stage III/IV ovarian cancer treated with surgery and HIPEC after NAC using PTX had better survival outcomes than those treated with surgery without HIPEC [21]. In a study by Bae et al., there was significant improvement in survival for the group treated with HIPEC using paclitaxel or carboplatin; (3-year DFS was $56.3 \%$ in the HIPEC group and $16.7 \%$ in the control group) ${ }^{[34]}$. 
With the inclusion of neoadjuvant laparoscopic HIPEC and intraoperative HIPEC as prophylaxis against peritoneal dissemination or treatment of occult peritoneal dissemination, the risk implications of preoperative chemotherapy and intra and post-operative complications are relatively high. However, based on previous literature involving ovarian and GC patients, the combination of HIPEC and NAC has been well tolerated and has shown to favor survival. Our study has shown that the NLHIPEC combined with NAC followed by surgery plus intraoperative HIPEC for AGC at risk of peritoneal carcinomatosis is feasibility and safe. In this study, we have weighed the complication risks of the different regimens in practice for AGC and we conclude that the different combinations involving HIPEC, NAC and surgery are all well-tolerated.

Limitations of the study: This study has been presented in the form of a retrospective case-matched case control study and the number of patients per group is small. The proposed comprehensive regimen is however assessed as safe and feasible but long-term survival with a larger pool of patients is still required to assess the efficacy of the proposed regimen and compare its significance with respect to the other treatment regimens. Nevertheless, it would be more plausible to investigate the plausibility of these results in a multicentre randomized controlled trial with a larger pool of patients.

\section{Conclusion}

The roles of intraoperative HIPEC and NAC have individually been investigated but the combination of HIPEC with NAC followed by surgery plus intraoperative HIPEC as a more extensive neoadjuvant and prophylactic approach for ACG has not been investigated before. This combination is worth exploring since it shows theoretical promise as a prophylaxis against PC before and after gastrectomy. The results of this study conclude that the proposed comprehensive regimen involving NLHIPEC combined with NAC followed by Surgery plus intraoperative HIPEC for Advanced Gastric Cancer at risk of Peritoneal Carcinomatosis is feasible and safe.

\section{Declarations}

Funding: No funding applicable.

Conflicts of interest/Competing interests: The authors hereby no conflict of interest.

Author's Contribution: MKB performed the literature review, study design and analysis and wrote the manuscript. ZTN assisted MKB in the research process, statistical analysis and redaction of the manuscript. WTL edited the manuscript, provided professional guidance and approved the manuscript. YXX, YM and ZGZ provided professional guidance and approved the manuscript.

Ethics approval: This study was approved by the Ethics Committee of Ruijin Hospital affiliated to Shanghai Jiao Tong University School of Medicine.

Consent to participate: Written consent was obtained from the subjects. 
Consent for publication: Written consent was obtained for approval to publish the observation results.

Availability of data and material: The data and materials are available on request.

Acknowledgement: Not applicable.

\section{References}

[1] Bray F, Ferlay J, Soerjomataram I, Siegel RL, Torre LA, Jemal A. Global cancer statistics 2018: GLOBOCAN estimates of incidence and mortality worldwide for 36 cancers in 185 countries. CA Cancer J Clin. 2018;68(6):394-424. doi: 10.3322/caac.21492.

[2] Gao K, Wu J. National trend of gastric cancer mortality in China (2003-2015): a population-based study. Cancer Commun. 2019;39(1):24. doi: 10.1186/s40880-019-0372-x.

[3] Stephen R. Smalley, Jacqueline K. Benedetti, Daniel G. Haller, Scott A. Hundahl, Norman C. Estes, Jaffer A. Ajani, Leonard L. Gunderson, Bryan Goldman, James A. Martenson, J. Milburn Jessup, Grant N. Stemmermann, Charles D. Blanke, John S. Macdonald. Updated analysis of SWOG-directed intergroup study 0116: a phase III trial of adjuvant radiochemotherapy versus observation after curative gastric cancer resection. J ClinOncol. 2012;30:2327-2333. doi: 10.1200/JC0.2011.36.7136.

[4] Cunningham D, Allum WH, Stenning SP, Thompson JN, Van de Velde CJ, Nicolson M, Scarffe JH, Lofts FJ, Falk SJ, Iveson TJ, Smith DB, Langley RE, Verma M, Weeden S, Chua YJ, MAGIC Trial Participants. Perioperative chemotherapy versus surgery alone for resectable gastroesophageal cancer. N Engl J Med. 2006;355:11-20. doi: 10.1056/NEJMoa055531.

[5] Coccolini, F., Montori, G., Ceresoli, M., Cima, S., Valli, M. C., Nita, G. E. Ansaloni, L. (2016). Advanced gastric cancer: What we know and what we still have to learn. World journal of gastroenterology, 22(3), 1139-1159. doi:10.3748/wjg.v22.i3.1139

[6] Giulia Montori, Federico Coccolini, Marco Ceresoli, Fausto Catena, Nicola Colaianni, Eugenio Poletti, Luca Ansaloni. The treatment of peritoneal carcinomatosis in advanced gastric cancer: state of the art. Int J SurgOncol. 2014;2014:912418.

[7] Chan, Morris D, Rao, Chua T Intraperitoneal chemotherapy in ovarian cancer: a review of tolerance and efficacy. Cancer Manag Res. 2012;4:413-422.

[8] Spiliotis J, Halkia E, Lianos E, Kalantzi N, Grivas A, Efstathiou E, Giassas S. Cytoreductive surgery and HIPEC in recurrent epithelial ovarian cancer: a prospective randomized phase III study. Ann SurgOncol. 2015;22(5):1570-1575.

[9] Bakrin N, Bereder JM, Decullier E, Classe JM, Msika S, Lorimier G, Abboud K, Meeus P, Ferron G, Quenet F, Marchal F, Gouy S, Morice P, Pomel C, Pocard M, Guyon F, Porcheron J, Glehen O; FROGHI (FRench Oncologic and Gynecologic HIPEC) Group. Peritoneal carcinomatosis treated with cytoreductive surgery 
and Hyperthermic Intraperitoneal Chemotherapy (HIPEC) for advanced ovarian carcinoma: a French multicentre retrospective cohort study of 566 patients. Eur J SurgOncol. 2013;39(12):1435-1443.

[10]Koga S, Hamazoe R, Maeta M, Shimizu N, Murakami A, Wakatsuki T. Prophylactic therapy for peritoneal recurrence of gastric cancer by continuous hyperthermic peritoneal perfusion with mitomycin C. Cancer 1988;61:232-7. 10.1002/1097-0142(19880115)61:2<232::AID-CNCR2820610205>3.0.CO;2-U

[11]Fujimoto S, Shrestha RD, Kokubun M, Kobayashi K, Kiuchi S, Konno C, Ohta M, Takahashi M, Kitsukawa Y, Mizutani M. Positive results of combined therapy of surgery and intraperitoneal hyperthermic perfusion for far-advanced gastric cancer. Ann Surg 1990;212:592-6. 10.1097/00000658199011000-00005

[12] Yonemura Y, Shinbo M, Hagiwara A. Treatment for potentially curable gastric cancer patients with intraperitoneal free cancer cells. Gastroenterological Surg 2008;31:802-12.

[13] Zhu ZG, Tang R, Yan M, Chen J, Yang QM, Li C, Yao XX, Zhang J, Yin HR, Lin YZ.. Efficacy and safety of intraoperative peritoneal hyperthermic chemotherapy for advanced gastric cancer patients with serosal invasion. A long-term follow-up study. Dig Surg 2006;23:93-102. 10.1159/000093778

[14] Li C, Yan M, Chen J, Xiang M, Zhu ZG, Yin HR, Lin YZ. Surgical resection with hyperthermic intraperitoneal chemotherapy for gastric cancer patients with peritoneal dissemination. J SurgOncol 2010;102:361-5. 10.1002/jso.21628

[15] Beeharry MK, Zhu ZL, Liu WT, Yao XX, Yan M, Zhu ZG. Prophylactic HIPEC with radical D2 gastrectomy improves survival and peritoneal recurrence rates for locally advanced gastric cancer: personal experience from a randomized case control study.BMC Cancer. 2019 Sep 18;19(1):932. doi: 10.1186/s12885-019-6125-z.

[16] Xu W, Beeharry MK, Liu W, Yan M, Zhu Z. Preoperative Chemotherapy for Gastric Cancer: Personal Interventions and Precision Medicine. Biomed Res Int. 2016;2016:3923585.

[17] Ronellenfitsch U, Schwarzbach M, Hofheinz R, Kienle P, Kieser M, Slanger TE, Jensen K; GE Adenocarcinoma Meta-analysis Group. Perioperative chemo(radio)therapy versus primary surgery for resectable adenocarcinoma of the stomach, gastroesophageal junction, and lower esophagus. Cochrane Database Syst Rev. 2013;5:CD008107.

[18] Cui H. B., Ge H. E., Bai X. Y., Zhang W., Zhang Y. Y., Wang J., Wang, Z. Y. (2014). Effect of neoadjuvant chemotherapy combined with hyperthermic intraperitoneal perfusion chemotherapy on advanced gastric cancer. Experimental and therapeutic medicine, 7(5), 1083-1088. doi:10.3892/etm.2014.1599

[19] Coccolini F, Celotti A, Ceresoli M, et al. Hyperthermic intraperitoneal chemotherapy (HIPEC) and neoadjuvant chemotherapy as prophylaxis of peritoneal carcinosis from advanced gastric cancer-effects 
on overall and disease free survival. J Gastrointest Oncol. 2016;7(4):523-529. doi:10.21037/jgo.2016.06.05

[20] Gao T, Huang XX, Wang WY, Wu MF, Lin ZQ, Li J. Feasibility and safety of neoadjuvant laparoscopic hyperthermic intraperitoneal chemotherapy in patients with advanced stage ovarian cancer: a singlecenter experience. Cancer Manag Res. 2019;11:6931-6940. Published 2019 Jul 24. doi:10.2147/CMAR.S213882.

[21] Cascales-Campos PA, López-López V, Torres-Melero J, Arjona A, Muñoz-Casares FC, Barrios P, Morales R, Pereira F, Bretcha-Boix P, González-Bayón L, González-Moreno S, Gil J. Survival outcomes in patients aged 75 years and over with peritoneal colorectal carcinomatosis after cytoreductive surgery and hyperthermic intraperitoneal chemotherapy (HIPEC): multicenter study of the Spanish Group of Peritoneal Cancer Surgery (GECOP). Clin Transl Oncol. 2019 May 2. doi: 10.1007/s12094-019-02124-9.

[22] Yonemura $Y$, Ishibashi H, Hirano M, Mizumoto A, Takeshita K, Noguchi K, Takao N, Ichinose M, Liu Y, $\mathrm{Li}$ Y. Effects of neoadjuvant laparoscopic hyperthermic intraperitoneal chemotherapy and neoadjuvant intraperitoneal/systemic chemotherapy on peritoneal metastases from gastric cancer. Ann Surg Oncol. 2017;24(2):478-485. doi:10.1245/s10434-016-5487-6

[23] Bălescu I, Godoroja D, Gongu M, Tomulescu V, Copăescu C. Laparoscopic HIPEC for Peritoneal Carcinomatosis from Gastric Cancer - Technique and Early Outcomes of Our First Cases. Chirurgia (Bucur). 2017 Nov-Dec;112(6):714-725. doi: 10.21614/chirurgia.112.6.714.

[24] Banda, J. M., Evans, L., Vanguri, R. S., Tatonetti, N. P., Ryan, P. B., \& Shah, N. H. (2016). A curated and standardized adverse drug event resource to accelerate drug safety research. Scientific data, 3, 160026. doi:10.1038/sdata.2016.26

[25] Schwartz, L. H., Seymour, L., Litière, S., Ford, R., Gwyther, S., Mandrekar, S. de Vries, E. (2016). RECIST 1.1 - Standardisation and disease-specific adaptations: Perspectives from the RECIST Working Group. European journal of cancer (Oxford, England : 1990), 62, 138-145. doi:10.1016/j.ejca.2016.03.082

[26] Dindo D, Demartines N, Clavien PA. Classification of surgical complications: a new proposal with evaluation in a cohort of 6336 patients and results of a survey. Ann Surg. 2004 Aug;240(2):205-13.

[27] Sasako M, Sakuramoto S, Katai H, Kinoshita T, Furukawa H, Yamaguchi T, Nashimoto A, Fujii M, Nakajima T, Ohashi Y. Five-year outcomes of a randomized phase III trial comparing adjuvant chemotherapy with S-1 versus surgery alone in stage II or III gastric cancer. J ClinOncol. 2011;29(33):4387-93.

[28] Noh SH, Park SR, Yang HK, Chung HC, Chung IJ, Kim SW, Kim HH, Choi JH, Kim HK, Yu W, Lee JI, Shin DB, Ji J, Chen JS, Lim Y, Ha S, Bang YJ; CLASSIC trial investigators.. Adjuvant capecitabine plus oxaliplatin for gastric cancer after D2 gastrectomy (CLASSIC): 5-year follow-up of an openlabel, randomised phase 3 trial. Lancet Oncol. 2014;15(12):1389-96. 
[29] Lee J, Lim DH, Kim S, Park SH, Park JO, Park YS, Lim HY, Choi MG, Sohn TS, Noh JH, Bae JM, Ahn YC, Sohn I, Jung SH, Park CK, Kim KM, Kang WK. Phase III trial comparing capecitabine plus cisplatin versus capecitabine plus cisplatin with concurrent capecitabine radiotherapy in completely resected gastric cancer with D2 lymph node dissection: the ARTIST trial. J ClinOncol 2012;30(3):268-73.

[30] Li Y., Zhou Z. Role and management of cancer clinical database in the application of gastric cancer precision medicine. Zhonghua Wei Chang Wai KeZaZhi. 2016;19:132-137

[31] Di Giorgio A, De laco P, De Simone M, Garofalo A, Scambia G, Pinna AD, Verdecchia GM, Ansaloni L, Macrì A, Cappellini P, Ceriani V, Giorda G, Biacchi D, Vaira M, Valle M, Sammartino P. Cytoreduction (Peritonectomy Procedures) Combined with Hyperthermic Intraperitoneal Chemotherapy (HIPEC) in Advanced Ovarian Cancer: Retrospective Italian Multicenter Observational Study of 511 Cases. Ann Surg Oncol. 2017 Apr;24(4):914-922. doi: 10.1245/s10434-016-5686-1.

[32] Coccolini F, Campanati L, Catena F, Ceni V, Ceresoli M, Jimenez Cruz J, Lotti M, Magnone S, Napoli J, Rossetti D, De laco P, Frigerio L, Pinna A, Runnebaum I, Ansaloni L. Hyperthermic intraperitoneal chemotherapy with cisplatin and paclitaxel in advanced ovarian cancer: a multicenter prospective observational study. J Gynecol Oncol. 2015 Jan;26(1):54-61. doi: 10.3802/jgo.2015.26.1.54.

[33] Muñoz-Casares FC, Medina-Fernández FJ, Arjona-Sánchez Á, Casado-Adam Á, Sánchez-Hidalgo JM, Rubio MJ. Peritonectomy procedures and HIPEC in the treatment of peritoneal carcinomatosis from ovarian cancer: long-term outcomes and perspectives from a high-volume center. Eur J SurgOncol. 2016;42:224-233.

[34] Bae JH, Lee JM, Ryu KS, Lee YS, Park YG, Hur SY. Treatment of ovarian cancer with paclitaxel- or carboplatin-based intraperitoneal hyperthermic chemotherapy during secondary surgery. GynecolOncol. 2007;106:193-200.

\section{Figures}




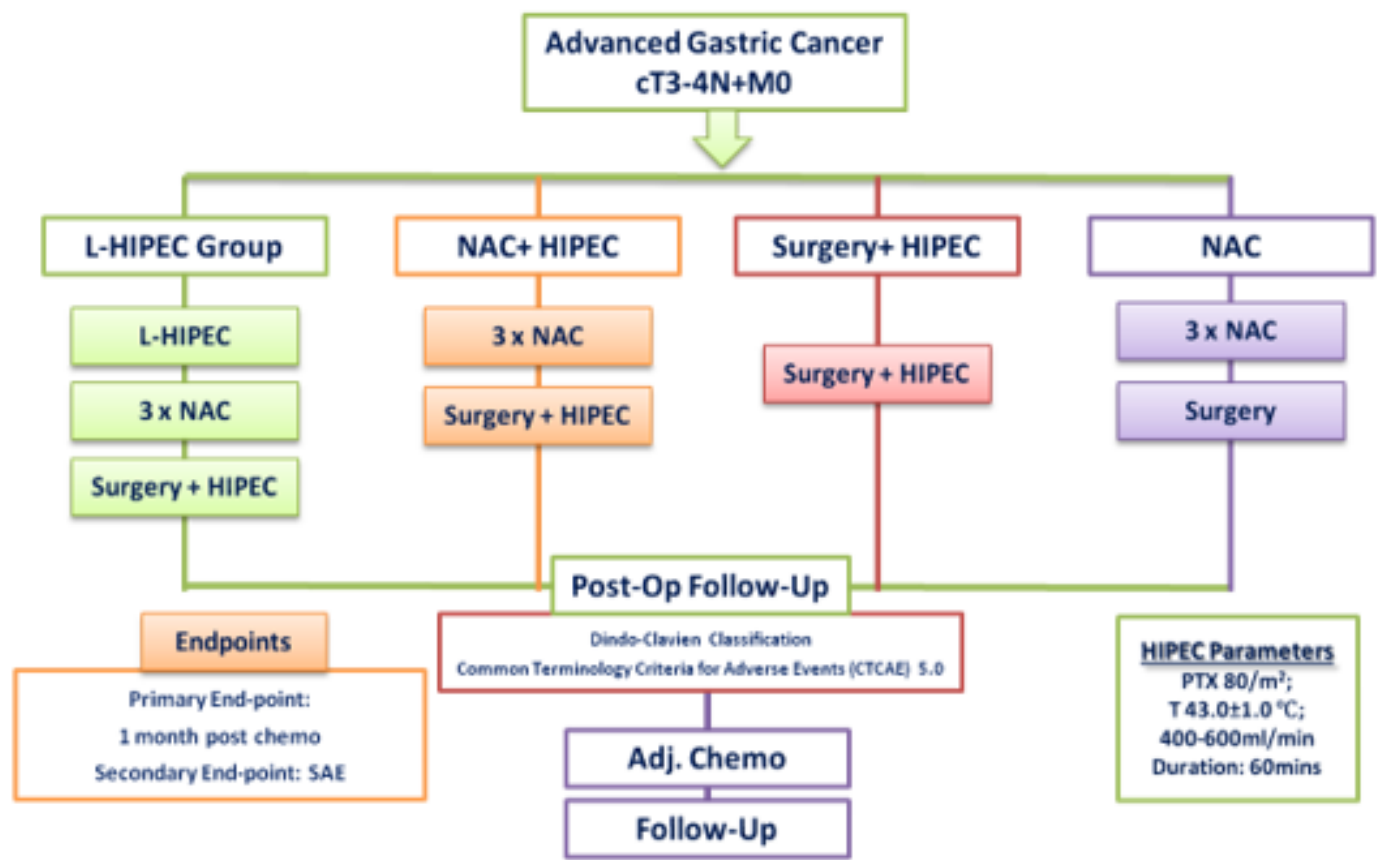

Figure 1

Patient Grouping and Treatment

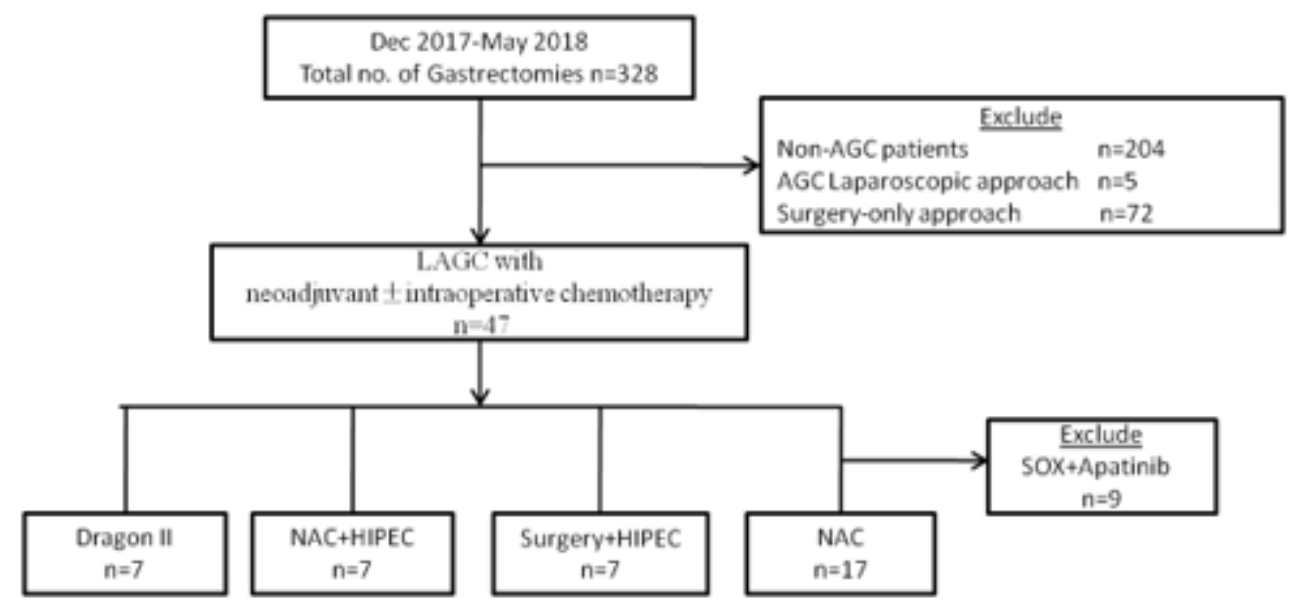

Figure 2

Study Flow Diagram 